\section{The use of breastfeeding pillow to reduce discomfort for breastfeeding mothers}

\author{
Ida Ayu Kade Sri Widiastuti1,2, \\ Yeni Rustina1, Defi Efendi1,3 \\ 1 Faculty of Nusing, Universitas \\ Indonesia; ${ }^{2}$ Diploma of Nursing, \\ Mulawarman University; ${ }^{3}$ Neonatal \\ Intensive Care Unit, Universitas \\ Indonesia Hospital, Indonesia
}

\begin{abstract}
The process of breastfeeding for newborns in the special care room often experiences obstacles due to diverse factors, such as environmental factors, hospitalization impact, and maternal discomfort during breastfeeding. The aim of this study was to determine whether breastfeeding pillows decrease maternal discomfort during breastfeeding. This research employed a randomized control trial (RCT) design involving 70 participants who were divided into an intervention $(n=35)$ and a control group $(n=35)$ based on the inclusion criteria. The intervention group used a breastfeeding pillow while breastfeeding the baby, and the control group provided ASI (breast milk) as recommended in the treatment room. The data measurement instruments were an observation sheet and the body part discomfort scale (BPDS). The BPDS comprised 4 assessments: the initial assessment, day I assessment, day II assessment, and the final assessment. The results of the GLM-RM analysis showed a significant reduction in maternal discomfort among participants using breastfeeding pillows $(\mathrm{P}<0.05)$. Supporting facilities such as breastfeeding pillows are needed to improve maternal comfort to increase the breastfeeding period
\end{abstract} and ensure optimal nutrition.

\section{Introduction}

Fulfilling the nutritional needs of sick infants who are hospitalized is a challenge that should be examined and developed by health workers. ${ }^{1}$ There are a lot of factors that contribute to inadequate breastfeeding. For example, in addition to the baby's immaturity factor, maternal discomfort factor is considered to be one of the breastfeeding problems. There are various complaints which are frequently experienced by the mother during the breastfeeding period.

According to the study confirmed that during breastfeeding $96 \%$ of mothers complain of discomfort in three areas of the body, namely lower abdomen, lower back and breasts. ${ }^{2}$ Sitting too long while breastfeeding often causes back discomfort. ${ }^{3}$ Using a breastfeeding pillow is expected to minimize maternal discomfort during the breastfeeding process.

\section{Materials and Methods}

The research design used was a randomized control trial (RCT) design, which involve an intervention group who used breastfeeding pillow and control group provided ASI (breast milk) as recommended in the treatment room. This study used a consecutive sampling technique with block randomization as a sampling technique. The inclusion criteria were babies (i) $32-40$ weeks of gestational age and/or a correction age $\geq 34$ weeks with a birth weight $\geq 2000$ grams, (ii) of all parous, and (iii) without congenital disease or defects. The exclusion criteria were (i) babies who had experienced deterioration, (ii) the mother was sick or died, and (iii) the mother had problems with her breasts (mastitis, flat nipples, and tumors)

Next, the sample size calculation used a different formula of two means. The mean value of the control group was 3.9 , while the mean value of the intervention group was 4.7. Furthermore, the standard deviation of the control group was 1.1, and the standard deviation was 1.2 in the intervention group. 4 The level of confidence was set at $\alpha=0.05$; the power of test was $80 \%$; and the estimation of the second variant of the group was 1.3 and $\pi 1-\pi 2=0.8$. We found that at least $n 1$ $=\mathrm{n} 2=31$ respondents, with a drop-out correction of $10 \%$ to 35 participants per group (Figure 1). The study was conducted in the Perinatology room of a hospital in Jakarta for 2 months. Ethical Clearance was issued by the Ethical Committee of the Faculty of Nursing of Universitas Indonesia (No. 15/UN2.F12.D/HKP.02.04/2019).

The intervention was carried out by giving breastfeeding pillows to participants in the intervention group every time they breastfed their babies over four days. The control group provided breast milk, as recommended in the treatment room, without using a breastfeeding pillow. Each breastfeeding period was conducted for 20-45 minutes, with an average length of 10-21 minutes. The breastfeeding pillow was made of cotton and grade A microfiber and had a soft texture. The pillow was deemed safe to use and measured $65 \mathrm{~cm} \times 50 \mathrm{~cm} \mathrm{x} 18 \mathrm{~cm}$.

Measurements were made four times: at the initial assessment, the day I assessment, the day II assessment, and the final assessment. The initial assessment was carried out
Correspondence: Yeni Rustina, Pediatric Nursing Department, Faculty of Nursing, Universitas Indonesia, Jalan Prof. Dr. Bahder Djohan, Kampus UI Depok, West Java, 16424 Indonesia.

Tel.: +6221.78849120 - Fax: +6221.7864124.

E-mail: y_rustina@ui.ac.id

Key words: Premature; nutrition; discomfort; breastfeeding pillow; attachment.

Acknowledgments: The writer expresses gratitude to all respondents and their families, the Perinatology nurses at Dr. Cipto Mangunkusumo Hospital Jakarta.

Funding: This study was supported by Hibah PITTA B 2019, funded by DRPM Universitas Indonesia (No. NKB.0505/UN2.R3.1/HKP.05. 00/2019).

Contributions: IAKSW designed research, conduct research, collect data, wrote the manuscript in consultation on with YR, DE. YR and DE verified the analytical methods. All authors discussed the results and contributed to the final manuscript.

Ethical approval: This research has obtained ethical approval from the Faculty of Nursing Universitas Indonesia (No. 15/UN2.F12.D/ HKP.02.04/2019).

Conflict of interest: The authors declare that authors have no conflict of interest.

This work is licensed under a Creative Commons Attribution NonCommercial 4.0 License (CC BY-NC 4.0).

(C)Copyright: the Author(s), 2020

Licensee PAGEPress, Italy

Pediatric Reports 2020; 12(s1):8702

doi:10.4081/pr.2020.8702

when the participants breastfed their babies without using a breastfeeding pillow. The day I assessment was conducted when the participants of the intervention group had used breastfeeding pillows for three breastfeeding schedules within one day. The control groups continued their regular breastfeeding routine in the treatment room without using a breastfeeding pillow. The assessment of day II was done in the same way as the day I assessment. The final assessment was performed on the following day. During the study, participants were given information and demonstrations about the effective breastfeeding process.

Maternal comfort of breastfeeding was measured by using the Body Part Discomfort Scale (BPDS). The measurement used a five-point Likert-type scale ranging from $1=$ comfortable to $5=$ 
extremely uncomfortable. The lowest measurement value was 9 , meaning and the highest score was 54, meaning extremely uncomfortable. The value of validity and reliability of the instrument was unknown; however, many researchers have previously used this instrument within their research.512 The study involved 2 observers by using a Kappa test value for testing inter-observer reliability. The result was 0.759 . This means that the perception between the researcher and the data collector is the same.

A Chi squared test $(2 \times 2)$ and the Mann Withney Test were used to determine homogeneity. The General Linear ModelRepeated Measure (GLM-RM) test was applied to determine whether effect differences were evident in the breastfeeding pillow usage towards the decline of maternal discomfort between the initial and the final assessment.

\section{Results}

1. Respondent characteristic description (Table 1)

2. Maternal discomfort analysis during Breastfeeding in the Intervention Group and Control Group Figure 2. Shows the area of discomfort felt by the participants in the initial assessment during breastfeeding. Of the participants in the intervention group, 94.3\% felt discomfort in more than four areas of the body, including the head/neck, shoulders, arms, waist and/or back, compared to $82.9 \%$ of the participants in the control group. In the final assessment, $68.60 \%$ of participants in the intervention group did not feel discomfort during breastfeeding; however, $77.10 \%$ of participants in the control group still felt discomfort in four or more areas of the body; including the head/neck shoulders, arms, waist, and/or back.

Table 2. The results of the analysis showed that no differences existed in the initial assessment between the intervention and control groups $(\mathrm{P}>0.05)$. However, the analysis mean differences between the two groups showed that significant differences were evident between the maternal discomfort experienced during breastfeeding at the day I assessment, day II assessment, and final assessment in the intervention and control groups $(\mathrm{P}<0.05)$.

Figure 3. Shows a comparison of the

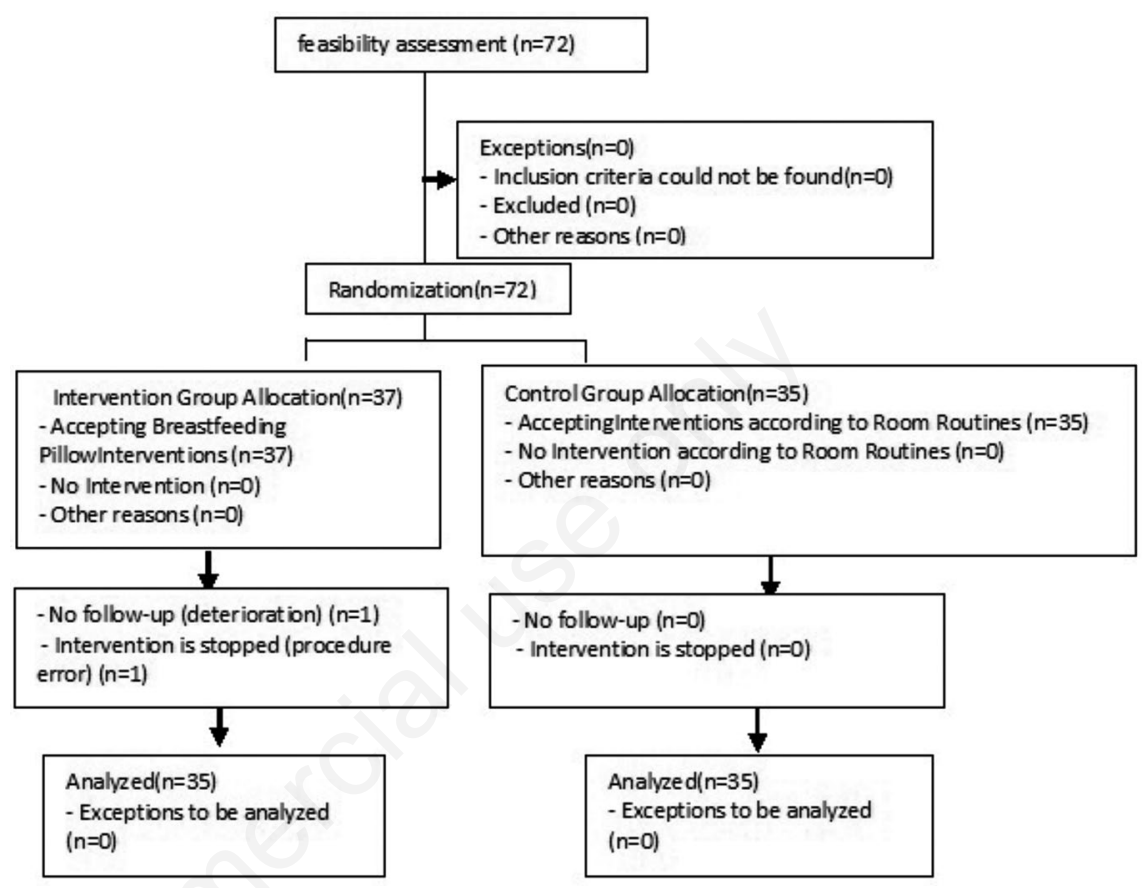

Figure 1. Data collection flow.

Table 1. Distribution of respondents based on gestation age, correction age, gender, method of birth, education, employment, and parity status of mother.

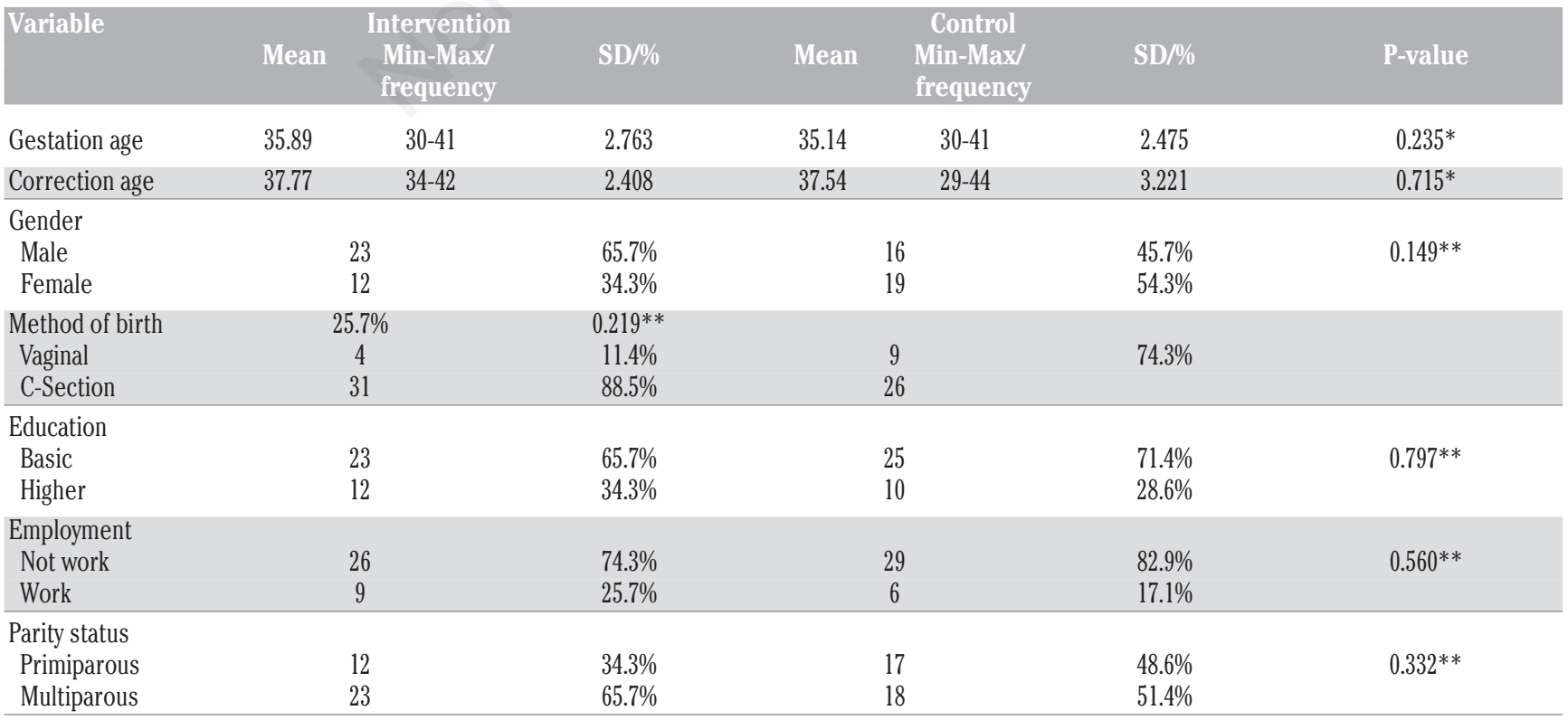

“*Uji Man Whitney, $\alpha<0.05 ; * *$ Uji Chi Square, $\alpha<0.05$." 
effect of using breastfeeding pillows on maternal discomfort. The measurements were made four times. Based on the mean diagram, the marginal estimation graph showed an increase in discomfort in the control group compares to a trend of decreasing discomfort in the intervention group.

\section{Discussion}

A prolonged discomfort during breastfeeding would make it difficult for mothers to adapt to their new role. The discomfort felt by the mother results from an inappropriate body posture and length of time sitting. 13 Typically, the mother's body attempts to maintain its position and attachment in a sitting position with straight back while leaning slightly forward. Such a position causes the mother's back muscles and waist to contract over time. The feeling of discomfort after breastfeeding usually occurs in the first two to three weeks after giving birth and could result in an ineffective breastfeeding process.

The goal of using a breastfeeding pillow is to achieve maternal comfort. This study found that the use of breastfeeding pillows was significantly effective in reducing maternal discomfort during breastfeeding between the day I assessment and the final assessment among participants in the intervention group.

The feeling of discomfort experienced among participants in the control group during breastfeeding was caused by a lack of support for the mother's arm. The position caused the shoulder muscles to contract to support the baby's weight. The condition of the postpartum mother increased the fatigue and discomfort. ${ }^{14}$ The study confirmed that divided the comfort or discomfort of the sitting position into three parts: initial comfort or discomfort, a short period ( $\leq 30$ minutes), and a long period ( $>30$ minutes). ${ }^{15}$ They reported that a mother's comfort would become discomfort after sitting for more than 30 minutes. ${ }^{15}$ In this study, the postpartum mothers experienced discomfort after sitting for less than 10 minutes. This can be interpreted as an inconvenience during the respondent's sitting is in a short period, which is less than 30 minutes.

According to the study confirmed that found a decrease in the degree of back pain when mothers used lumbar area support with a thickness of 9-11 cm for spinal sup- port. ${ }^{3}$ Sitting with a bent posture or a bend in the spine results in increased muscle tightening that causes fatigue and discomfort. The cause of the back discomfort was spinal degeneration manifested by muscle tension, usually found in people who used

\section{Area of Discomfort}

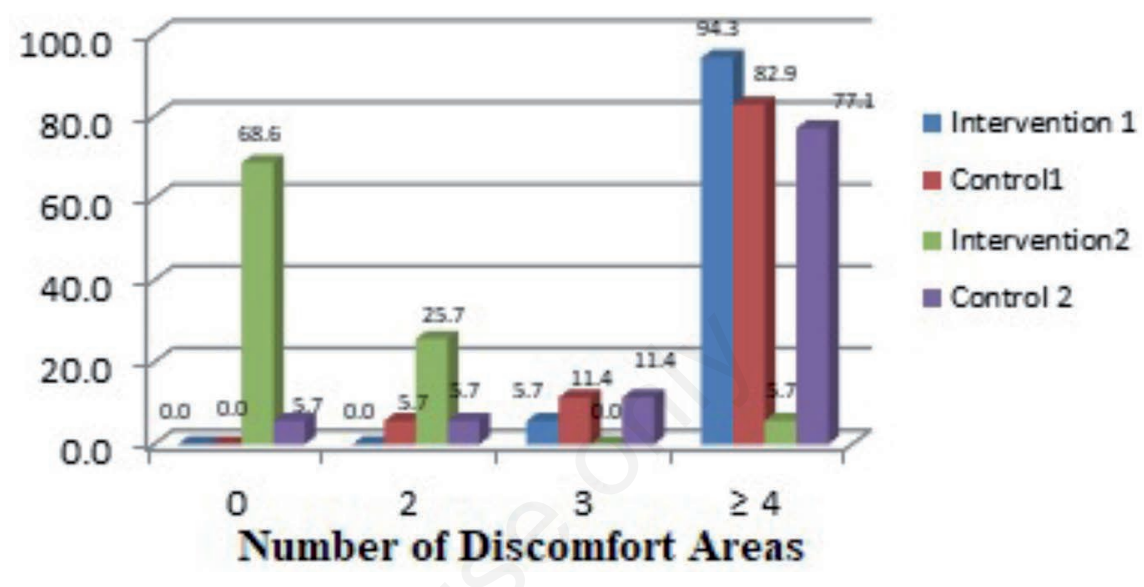

Figure 2. Frequency distribution based on the area of maternal discomfort in the preliminary and final assessments of the intervention and control group. $0=$ Comfortable; $2=$ Discomfort on 1-2 body areas; $3=$ Discomfort on 3 body areas; $4=$ Discomfort on 4 or 5 body areas.

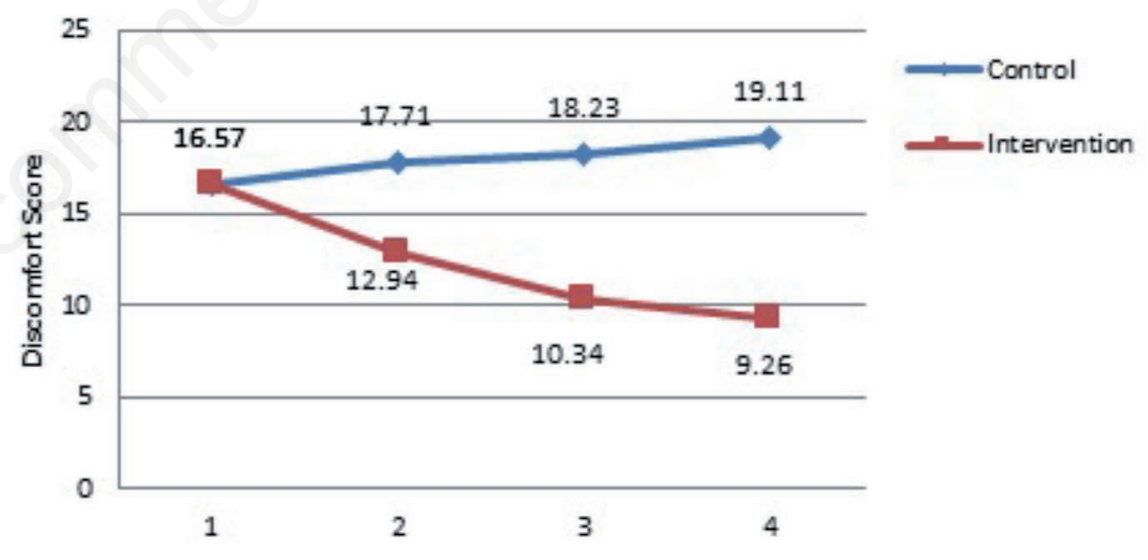

Figure 3. Comparison of the effect of breastfeeding pillow on reducing maternal discomfort in the intervention and control groups.

Table 2. Effect of use of breastfeeding pillows on decreasing maternal discomfort in control and intervention groups.

\begin{tabular}{|c|c|c|c|c|c|c|c|c|c|}
\hline Variable & & tervent & & & Control & & P-value & $95 \%$ confid & e interva \\
\hline uncomfortable & B & $\mathrm{t}$ & Mean & B & $\mathrm{t}$ & Mean & & Lower & Upper \\
\hline Initial assessment & 0.001 & -0.138 & 16.57 & - & - & 16.57 & 1.000 & 15.678 & 17.465 \\
\hline Day I assessment & -4.771 & -6.924 & 12.94 & - & - & 17.71 & 0.001 & 16.799 & 18.630 \\
\hline Day II assessment & $\begin{array}{l}-7.800 \\
-9.857\end{array}$ & - & 10.43 & - & 12.995 & 18.23 & 0.001 & 17.382 & 19.076 \\
\hline Final assessment & - & 9.26 & - & 20.685 & 19.11 & 0.001 & 18.442 & 19.787 & \\
\hline
\end{tabular}

Uji General Linier Model-Repeated Measure (GLM-RM) $\alpha<0.05$. 
excessive or inappropriate back muscles. ${ }^{16}$ Therefore, the breastfeeding process should be managed as comfortably as possible to avoid muscle tension.

The sitting position was found to result in $21 \%$ of participants' discomfort in the back, which caused intense spine and muscle tightening leading to fatigue and discomfort. 17 Therefore, to minimize back pain due to sitting, it is necessary to avoid sitting postures that could cause the back to bend. During breastfeeding, the mother's eyesight should always stay on her baby. However, this position could lead to feeling of discomfort due to contractions of the neck muscles from holding the head in a downward position for long period. Previous research had implicated that ineffective breastfeeding positions contribute to discomfort in the mother's arms and shoulders. 18 The study also explained that there were situations where the mother felt discomfort despite receiving guidance on breastfeeding positions. ${ }^{18}$

The breastfeeding position used in this study was a cradle hold position, which is a conventional and commonly practiced position for carrying babies. In this position, the mother's elbows support and lift the baby's neck, while the hands and lower arms supported the baby's head and buttocks. Besides cradle hold, there were several positions that could be used in breastfeeding, including a cross-cradle hold, lying back, and side-lying football. Although the study confirmed that there was no significant relationship exists between breastfeeding position and musculoskeletal problems in postpartum mothers, this study found that $36.8 \%$ of participants experienced neck pain, and $22 \%$ of participants experienced waist pain caused by a cross-sectional assessment of musculoskeletal problems. ${ }^{19}$ Thus, it was more likely that at the time of assessment, postpartum mothers had not yet experienced any disturbing musculoskeletal problems.

The study examined breastfeeding in a side-lying position and found that a breastfeeding pillow could reduce the weight of the baby's head on the mother's arm and upper arm on the feeding side, sustain the baby head position and synchronize the baby's mouth with the mother's nipple. ${ }^{14}$ However, side-lying breastfeeding could only be applied when the mother and the baby were in conjoint breastfeeding or when located at home. This study used only one breastfeeding position, the cradle hold the position, and almost all participants experienced discomfort in the five most common areas, namely the head/neck, shoulders, arms, back and waist. Even at the initial assessment, when the participants had not yet been exposed to a breastfeeding pillow, some participants already felt discomfort in other areas such as the thighs, knees, calves, and legs. This discomfort could be caused by muscle stiffness due to an ineffective breastfeeding position.

In the initial assessment, researchers found that $94 \%$ of participant in the intervention group and $82.9 \%$ of participants in the control group experienced discomfort in more than four areas because neither group had been exposed to treatment, i.e., they did not use a breastfeeding pillow when they breastfed their babies. The final assessment session found that $31.4 \%$ of the participant in the intervention group still experienced discomfort in the five most common areas. However, the number of areas and the level of discomfort felt by participants decreased. The study explained that the three body areas that often experience discomfort while sitting are the waist, buttock, and head/neck because these three body parts are heavier than the other body parts. ${ }^{12}$ Therefore, it is important to pay attention to breastfeeding position and the weight of the baby to avoid muscle tension.

The muscles involved in breastfeeding activities with a cradle hold position are brachii biceps, brachioradialis, serratus anterior, pectoralis major, pectoralis minor, and rhomboid muscles. ${ }^{14}$ Excessive contractions over a relatively long time could result in muscle stiffness. According to the study confirmed that musculoskeletal complaints generally occur due to excessive static muscle contraction caused by a heavy workload weight over a long period. 13 The study also explained that muscle complaints might not occur if muscle contractions fall between $15 \%-20 \%$ of the maximum muscle strength. If the contraction exceeded $20 \%$ of the maximum muscle strength, the circulation of blood and the supply of $\mathrm{O}_{2}$ to the muscles would decrease, the process of carbohydrate metabolism would also be hampered, and there could be an accumulation of lactic acid which causes pain in the muscles. However, the study failed to clarify what percentage of muscle contraction resulted from breastfeeding activities. ${ }^{13}$

Complaints of discomfort based on the measuring instruments used, namely the BPDS, ranged from very mild complaints to extremely uncomfortable. Perceptions of discomfort began from stimulation of the skin (exteroceptive); stimulation of sensors in the spindles of muscles, tendons, and joints (proprioceptive); stimulation of the internal organ system (interoceptive); and stimulation of the pain sensors (nociceptive). ${ }^{20}$ According to the study confirmed that the level of pain and physical vulnerability during breastfeeding caused $10 \%$ of mothers to stop breastfeeding their babies. ${ }^{21}$ Young mothers had a greater tendency to experience back pain compared to older mothers. ${ }^{3}$ In this study, almost all participants experienced back discomfort, whether primiparous, multiparous, or grand multiparous mothers. This was because new experiences and insufficient baby breastfeeding skills, especially in primiparous mothers, made breastfeeding mothers lack consideration for their bodies' position and comfort.

This study found that the main body parts experiencing discomfort during breastfeeding were head/neck, shoulders, arms, waist, and back, which were measured on a four-point scale of discomfort, ranging from uncomfortable to extremely uncomfortable. The feeling of discomfort, which was still felt by participants, was high when the breastfeeding pillow intervention was given; it was assigned a four, meaning very uncomfortable. Therefore, the intervention performed by providing a breastfeeding pillow aimed to lower the score on the scale of discomfort. It is expected that a low-level of discomfort could be tolerated by participants and could help them to breastfeed their babies maximally.

The baby's weight should also be considered because it increases the body's surface pressure. According to the study confirmed that an ergonomic work posture is recommended to improve the work effort and reduce pressure on the body. ${ }^{11}$ High pressure causes increased discomfort. ${ }^{11}$ In this study, breastfeeding activities were often carried out in a sitting position, but the participants were obliged to pay attention to their ergonomic posture.

The use of a soft seat was intended to prevent surface pressure. High surface pressure would suppress blood vessels and limit blood circulation, which could cause discomfort and muscular problems. ${ }^{17}$ Other related studies conducted by the study showed that the level of maternal fatigue after breastfeeding, which was measured by usage of breastfeeding pillow, decreased by $5.73 \% .13$ This showed that the ergonomic intervention could reduce the level of maternal fatigue/discomfort during the breastfeeding process. Therefore, it is essential to provide information to encourage mothers to pay attention to the principles of ergonomics during breastfeeding.

Breastfeeding pillows make the mother's position feel more comfortable and relaxed while breastfeeding. When a breastfeeding mother sat on a chair, the breastfeeding pillow would greatly support the baby's weight and thus prevent fatigue on the arm, shoulders, and neck of the moth- 
er. ${ }^{22}$ In addition, the muscles in the area directly involved during breastfeeding would not be contracted for a long time. This situation would ensure an adequate oxygen supply, allow the mother to feel relaxed, and thus maintain the physical condition of the mother during breastfeeding. Accordingly, this breastfeeding positions should be discussed with mothers in the discharge planning program as Julianti, Rustina and Efendi confirmed this topic influences the knowledge and skill of mothers who are ready to be discharged. ${ }^{23}$

\section{Conclusions}

The use of a breastfeeding pillow significantly decreases maternal discomfort experienced during the breastfeeding process. Maternal comfort is expected to enhance the quality of breastfeeding by improving the position and attachment of the mother-baby during the breastfeeding process, increasing the baby's sucking ability and the period of baby's breastfeeding to ensure optimal nutrition or improve the baby's suckling needs. A comfortable and relaxed condition can also suppress the release of stress hormones and increase the hormones that play a role in breast milk production. Thus, it is important to implement the use of a breastfeeding pillow among postpartum mothers.

\section{References}

1. Kearvel H, Grant J. Getting connected: How nurses can support mother/infant attachment in the neonatal intensive care unit. Aust J Adv Nurs 2010;27:75-82.

2. Holdcroft A, Snidvongs S, Cason A, et al. Pain and uterine contractions during breastfeeding in the immediate postpartum period increase with parity. Pain 2003;104:589-96.

3. Klinpikul N, Srichandr N, Poolthong N, Thavarungkul N. Factors affecting low back pain during breastfeeding of Thai women. World Academy of Science,
Engineering and Technology 2010;4: 254-7.

4. Aksu H, Küçük M, Gülergün DüzgünM. The effect of postnatal breastfeeding education/support offered at home 3 days after delivery on breastfeeding duration and knowledge: A randomized trial. J Matern Fetal Neonatal Med 2011;24:354-61.

5. Corlett EN, Bishop RP. A technique for assessing postural discomfort. Ergonomics. 1976;19:175-82.

6. Cameron JA. Assessing work-related body-part discomfort: Current strategies and a behaviorally oriented assessment tool. Int $\mathrm{J}$ Ind Ergonom 1996;18:389-98.

7. Liao MH, Drury CG. Posture, discomfort and performance in a VDT task. Ergonomics. 2000;43:345-59.

8. Lee I, Chung MK, Song YW. Relation between whole-body postural discomfort and body-part postures for working postures of automobile assembly tasks. Hum Fac Erg Soc P 2004;48:1397-401.

9. Drury CG, Atiles M, Chaitanya M, et al. Vicarious perception of postural discomfort and exertion. Ergonomics 2006;49:1470-85.

10. Hu B, Ma L, Zang W, et al. Can virtual reality predict body part discomfort and performance of people in realistic world for assembling tasks? Int J Ind Ergonom 2011; 41:64-71.

11. Goswami S, Haldar P, Sahu S. An ergonomic study of postural stress of nurses working in orthopedic wards. Int J Occup Saf Health 2013;3:26-31.

12. Li W, Yu S, Yang H, et al. Effects of long-duration sitting with limited space on discomfort, body flexibility, and surface pressure. Int J Ind Ergonom 2017; 58:12-24.

13. Muliarthini NW, Sutjana IDP, Adiatmika IGP. Penggunaan redesain bantal menyusui meningkatkan motivasi ibu menyusui dan kepuasan bayi serta mengurangi kelelahan dan keluhan muskuloskeletal ibu post partum. Jurnal Ergonomi Indonesia 2016;2:27-40.

14. Aoki M, Suzuki S, Takao H, Ikarashi F.
Pain related to breastfeeding in seated and side-lying positions: Assessment and recommendations for improved guidance. Journal of Ergonomic Technology 2017;7:43-59.

15. Zenk R, Mergl C, Hartung J, et al. Objectifying the comfort of car seats. In: SAE Technical Paper. SAE 2006 World Congress \& Exhibition: Proceedings of the 9th SAE Conference on Digital Human Modeling for Design and Engineering, 2006 April 3-6, Detroit, Michigan. Warrendale, PA: SAE International; 2006.

16. Campbell C, Muncer SJ. The causes of low back pain: A network analysis. So Sci Med 2005;60:409-19.

17. Beach TAC, Parkinson RJ, Stothart JP, Callaghan JP. Effects of prolonged sitting on the passive flexion stiffness of the in vivo lumbar spine. Spine J 2005;5:145-54.

18. Nakamoto T. Realities and challenges of breastfeeding support in neonatal nurses are doing. Academic archives of Yamaguchi Prefectural University (Bulletins and Records of Research Activities) 2013;6:33-41.

19. Rani S, Habiba UE, Qazi WA, Tassadaq N. Association of breastfeeding positioning with musculoskeletal pain in postpartum mothers of Rawalpindi and Islamabad. JPMA 2019;69:564-6.

20. Vink P, Hallbeck S. Editorial: Comfort and discomfort studies demonstrate the need for a new model. Appl Ergon 2012;43:271-6.

21. Dosier M. The effects of breastfeeding and breastfeeding in public: Looking at nursing nooks. [Unpublished paper]. San Luis Obispo: California Polytechnic State University; 2015.

22. Schanler RJ, Enger L. Patient education: Breastfeeding guide (beyond the basics). New York: Wolter Kluwer; 2018.

23. Julianti E, Rustina Y, Efendi D. Program perencanaan pulang dapat meningkatkan pengetahuan dan keterampilan ibu yang melahirkan bayi prematur merawat bayinya. Jurnal Keperawatan Indonesia 2019;22:74-81. 